\title{
Transfer of habituation using spreading depression'
}

\author{
LARRY R. SQUIRE 2 \\ MASSACHUSETTS INSTITUTE OF TECHNOLOGY
}

Rats exposed to a novel T-maze during unilateral spreading depression showed complete transfer of habituation when tested subsequently with depression of the opposite hemisphere.

Many studies have shown that, using the split-brain or spreading depression technique, information can be confined to the cerebral hemisphere which is active during learning (Sperry, 1961; Russell \& Ochs, 1961). It is of considerable interest, however, that sometimes information is not isolated, but instead transfers to the other hemisphere (Meikle \& Sechzer, 1960; Bures, Buresova, \& Fifkova, 1964). Furthermore, even in studies demonstrating lack of transfer, parts of the habit may be available to the opposite hemisphere. Ray \& Emley (1964), for example, noted that although rats showed no interhemispheric transfer of the correct turn at the choice point of a maze, they continued to respond with the same short latencies observed toward the end of original training. This result suggests that failure to transfer a specific discrimination habit need not imply a total failure to transfer other behavior patterns acquired in the same training situation. At the present time, a specification of transferable and nontransferable behavior patterns remains an unsolved problem. The experiment reported here sought to investigate whether habituation would show transfer.

Procedure

The apparatus was a small $\mathrm{T}$-maze of unpainted wood with stem and each arm $20 \mathrm{~cm}$ long, $14 \mathrm{~cm}$ high, and 10 $\mathrm{cm}$ wide. Under pentobarbital anesthesia, a hollow ring of Delrin $14 \mathrm{~mm}$ in diameter was placed on the exposed skull of a rat so as to encircle two trephine openings $2 \mathrm{~mm}$ in diameter. The ring waskept in place with dental cement and was covered with a prefitted, removable lid. Before testing, the lid was removed and unilateral spreading depression (USD) was elicited in each rat by placing cotton soaked with $10 \% \mathrm{KCl}$ through the trephine openings onto the exposed dura.

The experiment was designed to determine whether habituation to a simple environment during USD would be retained when the originally intact hemisphere was depressed. Twenty-six male, Long-Evans hooded rats $(200-250 \mathrm{gm})$ received USD. After loss of the placing reflex appeared on the side contralateral to the hemisphere depressed, animals were allowed to explore the maze for $4 \mathrm{~min}$. This procedure was repeated three additional times. The four sessions were conducted at $12 \mathrm{hr}$. intervals. The number of turning movements $\left(90^{\circ}\right.$ or $180^{\circ}$ counted as one turn) made during each 4-min. session served as the measure of habituation. Control animals $(\mathrm{N}=14)$ received USD in the order LLLR or RRRL for the four sessions. Experimental animals $(N=12)$ received USD in the order LLRL or RRLR for the four sessions.

\section{Results}

During the first session, the mean number of turns made by the animals with USD was 24.6 (range 14-40). During session 2, with the same hemisphere depressed, the mean number of turns dropped to 17.5 (range 5-31). This difference between turns during the two sessions was significant $(p<.01$, Wilcoxon matched-pairs, signed-ranks test). During the third session, there were no significant changes in turning scores for either experimental animals with USD on the opposite hemisphere or for control animals with USD on the same side as before. In particular, during this session there were no significant differences between the two groups ( $p>.05$, Mann-Whitney U test; see Fig. 1). The fourth session served as a replication and used only 19 of the original $26 \mathrm{Ss}$. Since the number of turning responses in the maze was unchanged when the locus of USD was shifted, it was concluded that this kind of habituation is not dependent on a restriction of information to the originally active hemisphere. It was also observed that Ss showed a strong tendency to turn in the direction ipsilateral to the depressed hemisphere. This tendency persisted on all test days, and indicated that habituation was not due to a selectively decreased tendency to make certain movements.

An additional group was run to test for the possibility that reduction in activity in both groups might be due to

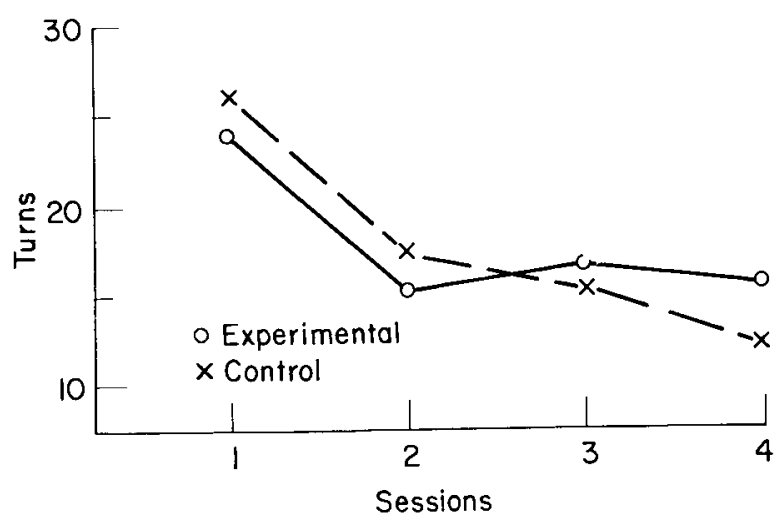

Fig. 1. Number of turns made by each group during successive 4 min. sessions. The administration of USD followed the sequence LLLR or RRRL for the control group and LLRL or RRLR for the experimental group. 
a general factor of handling. In each of two successive sessions, $12 \mathrm{hr}$. apart, 13 rats were given USD, handled, left in the test room for an hour, and returned to their home cages. Twelve hours later, all Ss were allowed to explore the maze for $4 \mathrm{~min}$. with USD on the same side. The mean number of turns was 26.5 (range 10-41), a value not significantly different from the score obtained by the previous groups in session 1 .

Discussion

This experiment demonstrates transfer of one kind of habituation. It is not clear what cues were used by Ss, nor whether the habituation resulted from interhemispheric transfer of information or was mediated by subcortical mechanisms unaffected by USD. The experiment suggests that general features of a training situation are available to the untested hemisphere during a subsequent test trial. The view that any given habit either wholly transfers or wholly fails to transfer is an oversimplification.

\section{References}

Bures, J., Buresova, o., \& Fifkova, E. Interhemispheric transfer of a passive-avoidance reaction. J. comp. physiol. Psychol., $1964,57,326-330$.

Meikle, T. H., \& Sechzer, J. A. Interocular transfer of brightness discrimination in "split-brain" cats, Science, 1960, 132, 734-735.

Ray, o. S., \& Emley, G. Time factors in interhemispheric transfer of learning. Science, 1964, 144, 76-78.

RusselI, I. S., \& Ochs, S. One-trial interhemispheric transfer of a learning engram. Science, 1961, 133, 1077-1078.

Sperry, R. W. Cerebral organization and behavior. Science, 1961, $133,1749-1757$.

\section{Notes}

1. This investigation was supported by USPHS grant RO1-MH 07923 to Dr. S. L. Chorover, whom I thank for interest and advice. This spreading depression technique was developed in our laboratory by Dr. P. H. Schiller.

2. NIH predoctoral fellow, 5-F1-MH-23, 520-02. 